\title{
Resveratrol-induced cytotoxicity in human Burkitt's lymphoma cells is coupled to the unfolded protein response
}

\author{
Ying Yan ${ }^{1,2}$, Yan-Yan Gao', Bao-Qin Liu', Xiao-Fang Niu', Ying Zhuang ${ }^{1}$, Hua-Qin Wang ${ }^{1 *}$
}

\begin{abstract}
Background: Resveratrol (RES), a natural phytoalexin found at high levels in grapes and red wine, has been shown to induce anti-proliferation and apoptosis of human cancer cell lines. However, the underlying molecular mechanisms are at present only partially understood.

Method: The effects of RES on activation of unfolded protein responses (UPR) were evaluated using Western blotting, semi-quantitative and real-time RT-PCR. Cell death was evaluated using Annexin V/PI staining and subsequent FACS.

Results: Similar as tunicamycin, treatment with RES lead to the activation of all 3 branches of the UPR, with early splicing of XBP-1 indicative of IRE1 activation, phosphorylation of elF2 $\alpha$ consistent with ER resident kinase (PERK) activation, activating transcription factor 6 (ATF6) splicing, and increase in expression levels of the downstream molecules GRP78/BiP, GRP94 and CHOP/GADD153 in human Burkitt's lymphoma Raji and Daudi cell lines. RES was shown to induce cell death, which could be attenuated by thwarting upregulation of CHOP.
\end{abstract}

Conclusions: Our data suggest that activation of the apoptotic arm of the UPR and its downstream effector CHOP/GADD153 is involved, at least in part, in RES-induced apoptosis in Burkitt's lymphoma cells.

\section{Background}

There is significant interest in naturally occurring bioactive products that have clinical potential in the prevention and treatment of cancer. Among them is resveratrol (RES), which belongs to a class of defense molecules called phytoalexins and is produced in a wide variety of plants (including grapes, peanuts, and mulberries) in response to stress, injury, UV irradiation, and fungal infection [1]. RES is normally present in many dietary products such as grapes, peanuts, berries and wine [2,3], which is known to affect a broad range of intracellular mediators involved in the initiation, promotion and progression of cancer [3-5]. As an anticancer agent, RES has pleiotropic effects, altering many different signaling pathways, leading to suppression of tumor cell proliferation, adhesion, invasion and metastasis, reduced signs of inflammation and angiogenesis, and induction of

\footnotetext{
* Correspondence: wanghq_doctor@hotmail.com

'Department of Biochemistry \& Molecular Biology, China Medical University, Shenyang 110001, China

Full list of author information is available at the end of the article
}

apoptosis and differentiation [4,6-13]. Nevertheless, although numerous studies have described intracellular changes leading to cell cycle arrest or apoptosis in response to RES treatment, the effects are often cell type specific $[14,15]$, the precise mechanisms associated with the anti-proliferative and chemopreventive effects of RES have not been well elucidated.

Recently, RES was shown to up-regulate a set of genes involved in endoplasmic reticulum (ER) stress response to unfolded proteins[16]. In addition, induction of CHOP/GADD153, one of the components of the ER stress-mediated apoptosis pathway, was shown to be implicated in RES-induced apoptosis in colon cancer cells [17]. Accordingly, evidence was reported more recently that RES could indeed trigger ER stress-induced cell death in dopaminergic cells[18]. UPR could therefore be a potential mechanism of RES cytotoxicity.

Conditions that disrupt protein folding in the ER, such as a chemical insult or nutrient deprivation, activate stress signaling pathways collectively termed as the unfolded protein response (UPR) $[19,20]$. The UPR is 
the major protective and compensatory mechanism enabling stressed cells to survive during ER stress. UPR induction results in both an initial decrease in general protein synthesis, to reduce the influx of nascent proteins into the ER, and increased transcription of ER resident chaperones, folding enzymes, and components of the protein degradative machinery to prevent the aggregation of the accumulating misfolded proteins. The key players in the UPR are well characterized and it is mediated through three ER transmembrane receptors: pancreatic ER kinase (PERK), activating transcription factor 6 (ATF6) and inositol-requiring enzyme 1 (IRE1) [21-23]. In resting cells, all of these ER stress receptors are maintained in an inactive state through their association with the ER chaperone, GRP78 (also called BiP). This interaction is destabilized in the presence of misfolded/unfolded proteins, resulting in the dissociation of GRP78/BiP from PERK, ATF6 and IRE1, thereby initiating the UPR. Initially, the UPR is a pro-survival response enabling the cell to survive reversible environmental stresses. However, if the stress is too severe or lasts for too long, UPR activation eventually leads to cell-cycle arrest and the induction of apoptosis[24-29].

CHOP/GADD153 is a member of CCAAT/enhancerbinding protein family that is induced by ER stress and participates in ER stress-mediated apoptosis [30]. In this study we demonstrate that RES treatment indeed caused the activation of UPR in Raji and Daudi Burkitt's lymphoma cells. Our results demonstrate that a proportion of the ability of RES to kill Burkitt's lymphoma Raji and Daudi cells has been attributed to upregulation of CHOP/GADD153.

\section{Methods}

\section{Cell culture}

Human Raji and Daudi Burkitt's lymphoma cells, human HMy2.CIR B lymphoblast cells were grown as suspension culture in RPMI1640 medium supplemented with 10\% FBS. Resveratrol (Sigma-Aldrich, Inc., St. Luis, MO) was dissolved as a $100 \mathrm{mM}$ stock solution in DMSO.

\section{Viability assay}

The in vitro toxicology assay (methyl-thiazol-tetrazolium, MTT based) was performed according to manufacturer's instruction (KeyGEN, Nanjing, China). Cells $\left(1.5 \times 10^{4}\right.$ cells $\left./ 100 \mu \mathrm{l}\right)$ were incubated in a 96-well plate with different effectors for the times indicated in the figure legends.

\section{Cell death analysis}

For cell death assays, according to the manufacturer's instructions, cells were stained with Annexin V-FITC and propidium iodide (KeyGEN, Nanjing, China) and analyzed by fluorescence-activated cell scanner
(FACScan) flow cytometer (Becton Dickinson, Franklin Lakes, NJ).

\section{RT-PCR detection of unspliced and spliced XBP-1}

To determine relative expression levels of XBP-1/XBP-1 s within a sample, the XBP-1 cDNA fragment was amplified with the following pair of primers: 5'-GTTGAGAACCAGGAGTTAAGACAG-3' (forward) and 5'-CAGAGGGTATCTCAAGACTAGG-3' (reverse). A 456-bp PCR product was expected if the XBP-1 cDNA fragment was derived form the unspliced form (that contains the 26-bp intron) and a 430-bp PCR product was expected if the XBP-1 cDNA fragment is derived form the spliced form. The GAPDH fragment was amplified with the following pair of primers: 5'-CTCAGACACCATGGGGAAGGTGA-3' (forward) and 5'-ATGATCTT GAGGCTGTTGTCATA-3' (reverse) to produce a 450-bp fragment of GAPDH. The temperature profile was at $94^{\circ} \mathrm{C}$ for 2 minutes, followed by 30 cycles of $94^{\circ} \mathrm{C}$ for 15 seconds, $60^{\circ} \mathrm{C}$ for 1 minute, and $72^{\circ} \mathrm{C}$ for 30 seconds. The numbers of PCR amplification cycle of XBP-1 and GAPDH were 35 and 25 respectively. PCR products were run on $2 \%$ agarose gels containing ethidium bromide followed by visualization under UV.

\section{RNA isolation and real-time RT-PCR}

Total RNA was isolated from cells using TRIzol reagent (Invitrogen, Carlsbad, CA). Real time PCR analysis was performed in triplication on the ABI 7500 sequence detection system (Applied Biosystems, Foster City, CA) using the SYBR Green PCR Master mix (Applied Biosystems, Warrington, UK). For CHOP, the forward primer was $5^{\prime}$-ATGAGGACCTGCAAGAGGTCC-3' and the reverse was 5'-TCCTCCTCAGTCAGCCAAGC-3'. For GRP78, the forward primer was $5^{\prime}$-GTTCTTGCCG TTCAAGGTGG-3' and reverse was 5'-TGGTACAGTAACAACTGCATG-3'. For GRP94, the forward primer was 5'-TACCCACATCTGCTCCACGTG-3' and reverse was 5'-ACCAAGCTTGATGTTGGTAC-3'. For ATF4, the forward primer was $5^{\prime}$-AAGCCTAGGTCTCTTAGATG-3' and reverse was 5'-TTCCAGGTCATCTATACCCA-3'. For GADD34, the forward primer was 5'-AAGCTCACAGAACCTCTAC-3' and reverse was 5'-GATGTCCACAGAAGAACTTC-3'. For $\beta$-actin, the forward primer was 5'-GAGACCTTCAACACCCCAGCC-3' and the reverse was 5'-GGATCTTCATGAGGTAGTCAG-3'. All the reactions were performed in triplicate and normalized using $\beta$-actin as control gene.

\section{Western blot analysis}

Cells were lysed in lysis buffer $(20 \mathrm{mM}$ Tris- $\mathrm{HCl}$, $150 \mathrm{mM} \mathrm{NaCl}, 2 \mathrm{mM}$ EDTA, 1\% Triton-X100) 
containing a protease inhibitor cocktail (Sigma-Aldrich, Saint Louis, MO). Cell extract protein amounts were quantified using the BCA protein assay kit. Equivalent amounts of protein $(20 \mu \mathrm{g})$ were separated using $12 \%$ SDS-PAGE and transferred to PVDF membrane (Millipore Corporation, Billerica, MA). Western immunoblotting was performed using primary antibodies against CHOP (Santa Cruz Biotechnology, Santa Cruz, CA), GRP78 (BD Bioscience, San Diego, CA), GRP94 (Abcam, Cambridge, MA), ATF6 (Abcam, Cambridge, MA), eIF2a (Cell Signaling, Danvers, MA), phosphoeIF2a (Ser51) (Cell Signaling, Danvers, MA), phospoPERK (Thr980) (Cell Signaling, Danvers, MA), Histone H2B (Cell Signaling Technology, Danvers, MA), or GAPDH (Chemicon, Bedford, MA), horseradish peroxidase (HRP)-conjugated anti-rabbit or anti-mouse secondary antibodies (Amersham Biosciences, UK) and ECL solutions (Amersham Biosciences, UK).

\section{Small interfering RNA (siRNA)}

The siRNA sequences used here were as follows: siRNA against CHOP (siCHOP), AAGAACCAGCAGAGGUCACAA and scramble (CCGUAUCGUAAGCAGUACU) that has no homology to any known genes was used as control. In addition, position-mismatched (sequence underlined) siCHOP (simutCHOP; AAGAACCAGCAGACCUCACAA) was also used to confirm the specificity of siCHOP. Transfection of siRNA oligonucleotide was performed with Lipofectamine 2000 (Invitrogen, Carlsbad, CA) according to the manufacturer's recommendations. The cells were transfected on three consecutive days, and subsequent treatment was performed $72 \mathrm{~h}$ after the first transfection.

\section{Detection of $\mathrm{Ca}^{2+}$ concentrations}

The cytoplasmic level of $\mathrm{Ca}^{2+}$ was determined by flow cytometry (Becton Dickinson FACS Calibur), using Indo 1/AM (Calbiochem, La Jolla, CA). Cells were pretreated with vehicle or BAPTA, a $\mathrm{Ca}^{2+}$ chelator $(10 \mu \mathrm{M})$ for $3 \mathrm{~h}$ before adding $100 \mu \mathrm{M}$ RES for incubation for $24 \mathrm{~h}$ to detect the changes in $\mathrm{Ca}^{2+}$ concentration. The cells were harvested and washed twice, then resuspended in Indo $1 / \mathrm{AM}(3 \mu \mathrm{g} / \mathrm{ml})$ and incubated at $37^{\circ} \mathrm{C}$ for $30 \mathrm{~min}$ before being analyzed by flow cytometry.

\section{Statistics}

The statistical significance of the difference was analyzed by ANOVA and post hoc Dunnett's test. Statistical significance was defined as $p<0.05$. All experiments were repeated three times, and data were expressed as the mean \pm SD (standard deviation) from a representative experiment.

\section{Results}

Rapid phosphorylation of PERK and elF2 $\alpha$ in Raji and Daudi Burkitt's lymphoma cells treated with RES

PERK plays a particularly important role in mediating the global cellular response to ER stress. ER stress induces a PERK-dependent phosphorylation of the a subunit of eukaryotic initiation factor $2 \alpha$ (eIF2 $\alpha$ ), which leads to a generalized inhibition of translation to reduce the client protein load in the ER[31]. To determine whether this branch of UPR was activated in Burkitt's lymphoma cells treated with RES, we examined the levels of phosphorylated PERK and eIF2 $\alpha$ in cells treated with RES. Tunicamycin, a classical ER stress-inducing agent, was simultaneously used to treat Raji and Daudi cells as a positive control. Treatment of Raji and Daudi cells with RES for $8 \mathrm{~h}$ caused a marked increase in the phosphorylation of PERK and its direct intracellular substrate, eIF2 $\alpha$ (Figure 1A). The phosphorylation of PERK and eIF $2 \alpha$ was not associated with an increase in the abundance of these two proteins, suggesting that RES only causes an increase in the fraction of each of these two proteins to become phosphorylated. The time course of the phosphorylation of PERK and eIF2 $\alpha$ was then investigated in Raji leukemia cells. PERK phosphorylation was detected at $1 \mathrm{~h}$ and steady state of phosphorylation was reached at $4 \mathrm{~h}$ after RES exposure (Figure 1B). A similar time course for phosphorylation of eIF2 $\alpha$ was observed (Figure 1B). Because IF2a phosphorylation subsequently induces ATF4 and GADD34 [32], we next examined the induction of GADD34 and ATF4 mRNA after RES treatment by real-time PCR. RES, as well as tunicamycin, induced GADD34 (Figure 1C) and ATF4 (Figure 1D) mRNA in Raji and Daudi cells. These results indicate that RES induces a pathway initiated by phosphorylation of eIF $2 \alpha$ and followed by the upregulation of GADD34 and ATF4.

\section{Stimulation of XBP-1 splicing by RES in Raji and Daudi cells}

ER stress also induces activation of the IRE1 $\alpha$ endonuclease, which causes the unconventional splicing of XBP-1 mRNA (encoding a transcription factor) in the cytoplasm. The spliced form of XBP-1 mRNA acts as a transcription factor which induced the expression of ER-resident molecular chaperons during ER stress [31]. To evaluate the possible role in induction of IRE1 $\alpha$ / XBP-1 pathway by RES, total RNA was extracted from Raji and Daudi cells treated with RES for various time intervals and the XBP-1 was examined by RT-PCR with the primers described in materials and methods. Two binds of $456 \mathrm{bp}$ and $430 \mathrm{bp}$ with $26 \mathrm{bp}$ difference are expected to be amplified, representing the spliced and 
A

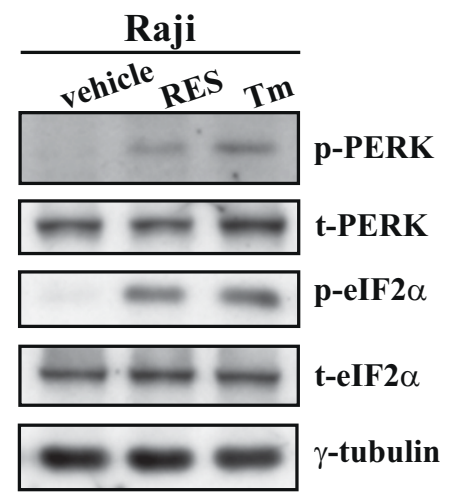

Daudi

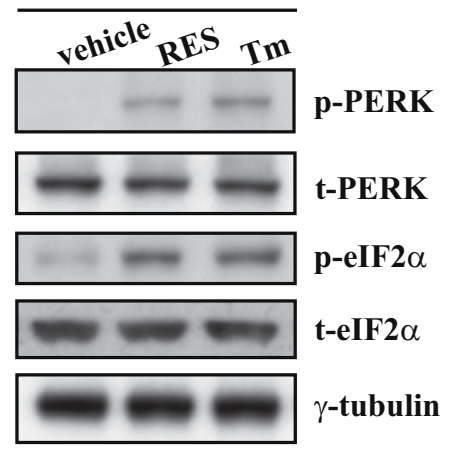

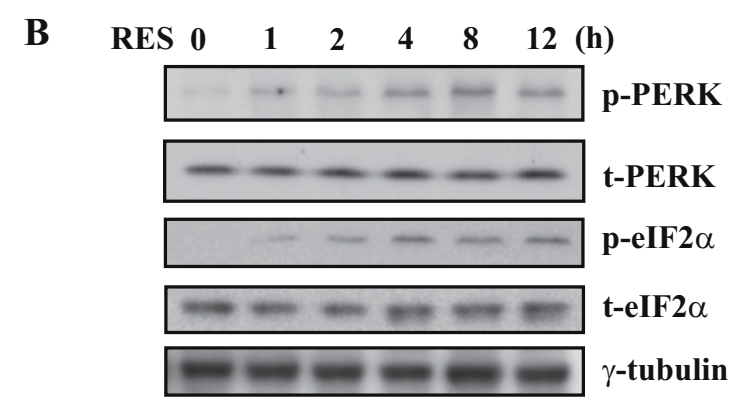
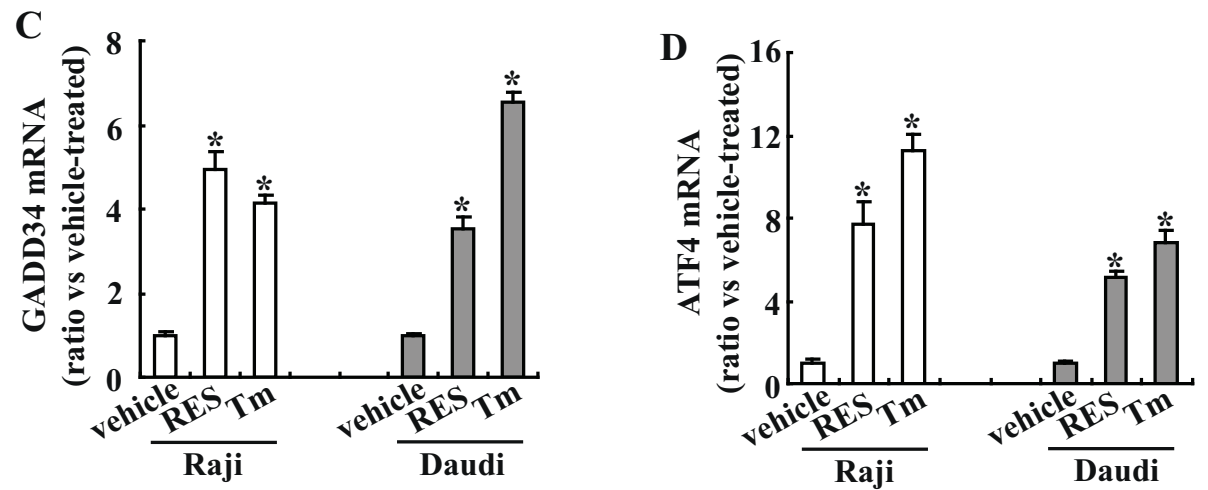

Figure 1 Activation of PERK and elF2 $\alpha$ signal pathway by RES in Raji and Daudi cells. A, Raji and Daudi cells were incubated with resveratrol (RES; $100 \mu \mathrm{M})$ or tunicamycin $(\mathrm{Tm} ; 10 \mu \mathrm{g} / \mathrm{ml})$ used as a positive control for $8 \mathrm{~h}$ and cell lysates were subjected to Western blotting analysis. B, Raji cells were treated with $100 \mu \mathrm{M}$ of RES for the indicated time, and Western blotting analysis was performed. C, Raji and Daudi cells were incubated with $100 \mu \mathrm{M}$ of RES or $10 \mu \mathrm{g} / \mathrm{ml}$ of Tm for $8 \mathrm{~h}$ and GADD34 mRNA levels were investigated using real-time PCR. D, Cells were treated as $C$ and ATF4 mRNA levels were analyzed. ${ }^{*}, P<0.01$.

unspliced mRNA of XBP-1, respectively. Only one XBP1 cDNA fragment corresponding to the unspliced XBP1 mRNA was detected in Raji cells after $4 \mathrm{~h}$ of RES treatment (Figure 2A). However, an additional XBP-1 cDNA fragment, corresponding to the spliced XBP-1 mRNA was formed as incubation was continued further ( $8 \mathrm{~h}$ and beyond) (Figure 2A). Although the early effects (within $12 \mathrm{~h}$ ) on XBP-1 splicing after exposure to RES were similar to that seen with tunicamycin, prolonged incubation (up to $24 \mathrm{~h}$ ) failed to induce further splicing (Figure 2A). A similar time course of generation of the spliced XBP-1 mRNA could be observed when Daudi cells were treated with RES (Figure 2B). The transcription factor protein XBP-1, which is translated from spliced XBP-1 mRNAs, contains a nuclear localization signal and a transcriptional activation domain and 


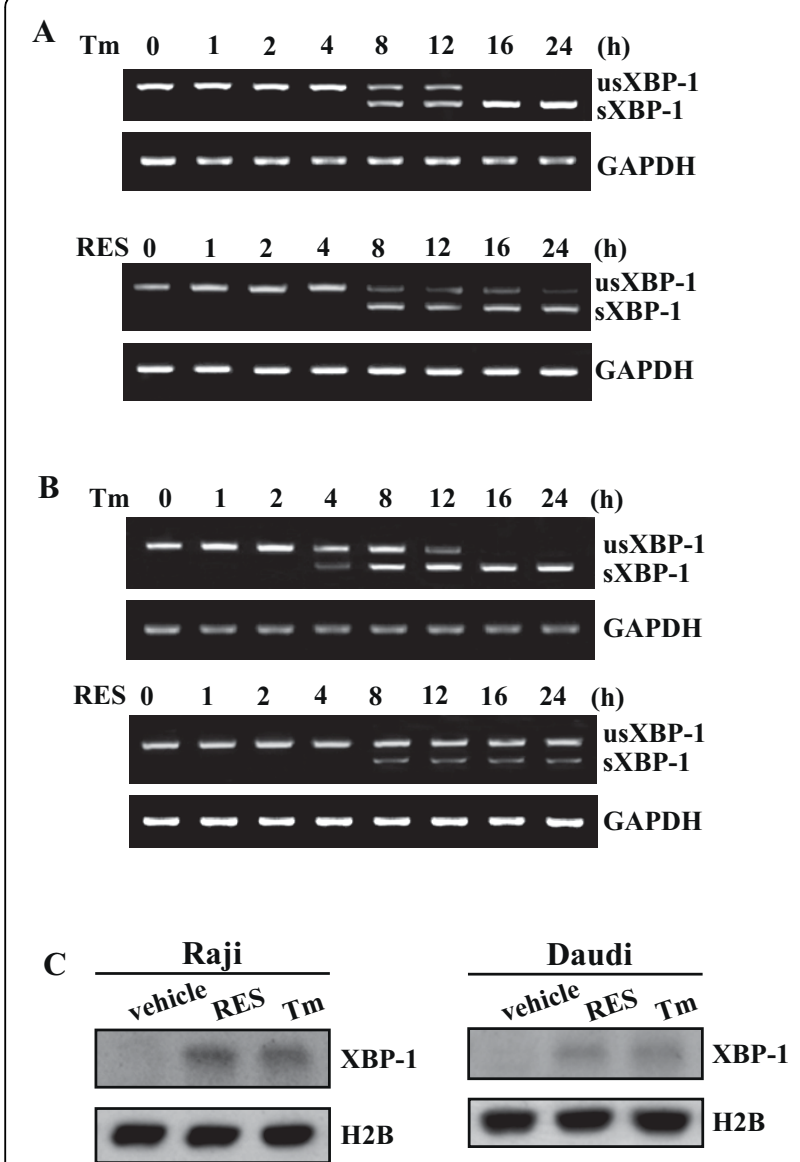

Figure 2 Stimulation of XBP-1 splicing in Raji and Daudi cells treated with RES. Raji (A) and Daudi (B) cells were incubated with $100 \mu \mathrm{M}$ of RES for the indicated time, total RNA was extracted form the cells and the mRNA of XBP-1 was detected and analyzed by RT$P C R$. The RT-PCR products were analyzed by agarose gel electrophoresis. GAPDH was used as the internal control. C, XBP-1 expression in nuclear lysates was analyzed using Western blot. The cells were treated with either $100 \mu \mathrm{M}$ of RES or $10 \mu \mathrm{g} / \mathrm{ml}$ of Tm for 8 h. Antibody against histone H2B was used as loading control.

activates the transcription of target genes in the nucleus. We then analyzed XBP-1 expression in the nuclear using Western blot analysis. Similar like tunicamycin, RES increased XBP-1 expression both in Raji and in Daudi cells (Figure 2C).

\section{Activation of ATF6 signaling pathway by RES in Raji and} Daudi Burkitt's lymphoma cells

In addition of eIF $2 \alpha$ phosphorylation and XBP-1 splicing, ER stress activates the ATF6-dependent pathway that subsequently induces the expression of many genes containing the ERSE in the promoter regions, including GRP78/BiP, calnexin, calreticulin, and XBP-1 [33,34]. ATF6 is an integral membrane protein that is found at the ER, upon ER stress, ATF6 is converted from a 90$\mathrm{kDa}$ protein (p90ATF6) to a 50-kDa protein (p50ATF6)

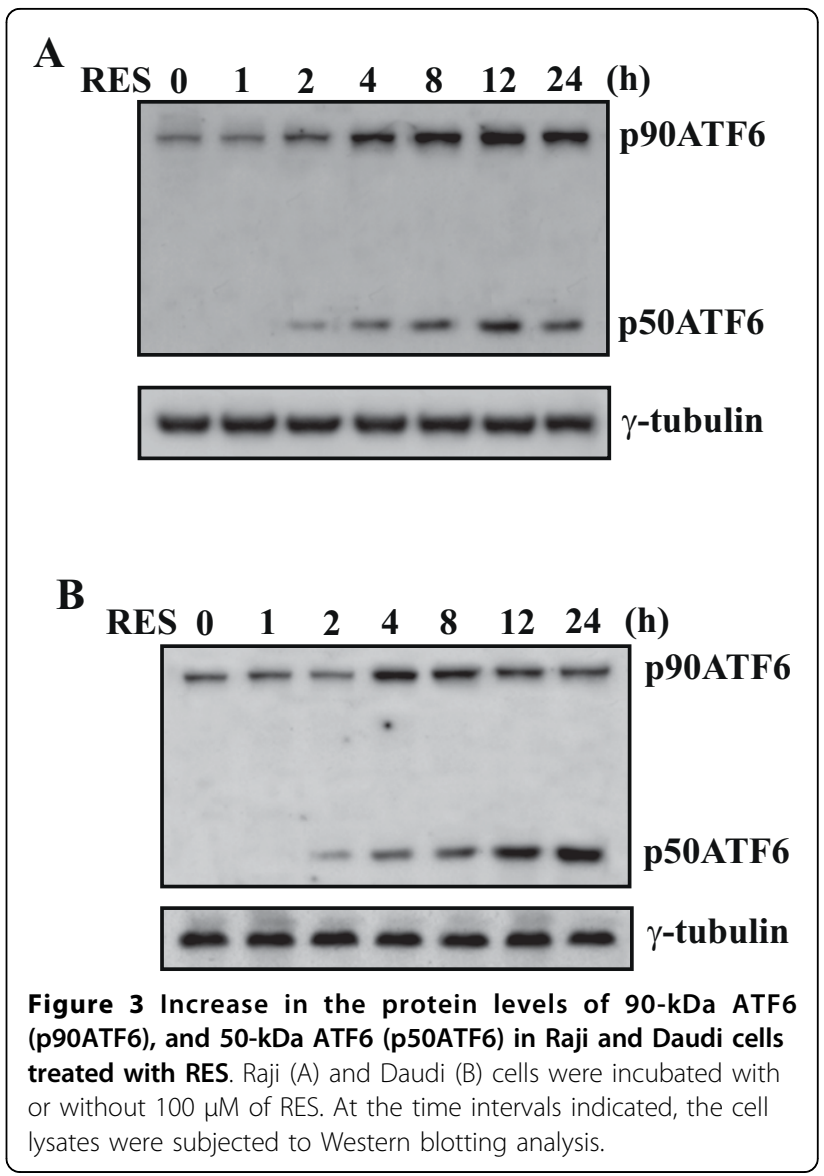

transcription factor, resulting in nuclear translocation [35]. Thus, we investigated whether RES induces p50ATF6 by Western blot. In the Raji cells, treatment with RES led to an increase in the protein levels of both the $90-\mathrm{kDa}$ and the $50-\mathrm{kDa}$ ATF6 after $2 \mathrm{~h}$ of stimulation (Figure 3A). Similarly, in the Daudi cells, the protein level of the $90-\mathrm{kDa}$ and $50-\mathrm{kDa}$ ATF6 substantially increased with a peak at 4-8 h after addition of RES (Figure 3B).

Induction of downstream effectors of UPR, GRP78/BiP and CHOP/GADD153 by RES in Raji and Daudi cells

GRP78/BiP is the key chaperone for folding and maturation of protein in ER and its upregulation is the usual marker of ER stress. The real-time PCR analyses indicated that GRP78/BiP in Raji and Daudi cells increased by approximately 12 and 20 fold after $100 \mu \mathrm{M}$ of RES exposure, respectively (Figure 4A). Western blot analysis confirmed that GRP78/BiP protein levels were also significantly increased in response to treatment with RES (Figure 4B). Compared with GRP78/Bip, lower induction of GRP94 were observed in response to RES, with only 3 - to 5-fold changes of mRNA transcript being detected with $100 \mu \mathrm{M}$ of RES treatment (Figure 4A), GRP94 
A
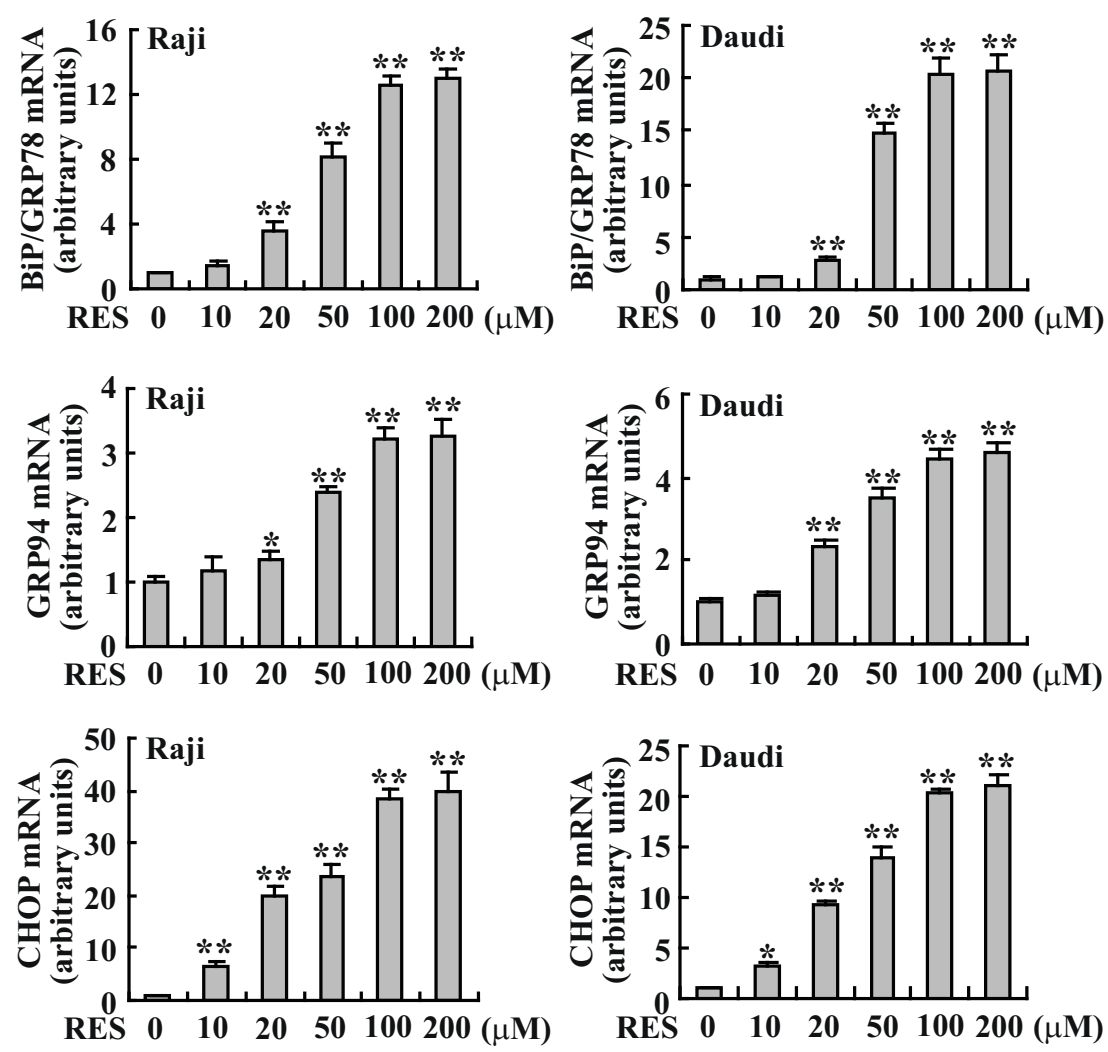

B

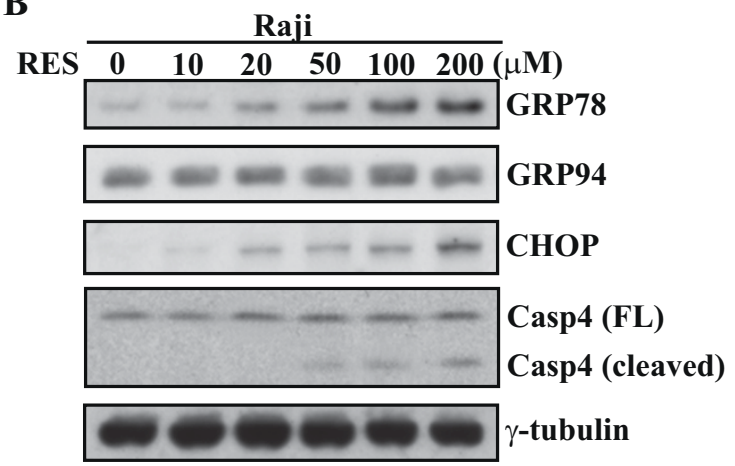

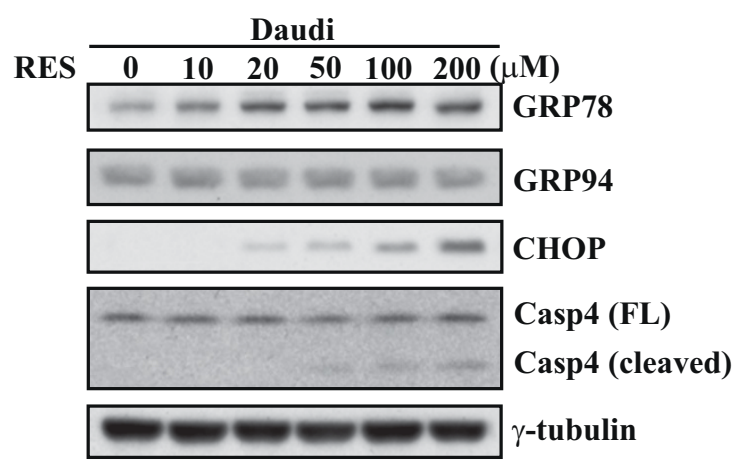

Figure 4 Induction of BiP/GRP78 and GADD153/CHOP expression by RES in Raji and Daudi cells. A, Raji and Daudi cells were treated with different concentration of RES for $8 \mathrm{~h}$ and real-time PCR was performed. B, Raji and Daudi cells were treated with the indicated concentration of RES for $24 \mathrm{~h}$ and cell lysates were subjected to Western blotting analysis. ${ }^{*}, P<0.05 ;{ }^{*}, P<0.01$.

protein levels demonstrated unaltered or marginal increase throughout this dose range (Figure 4B). Another usual marker of ER stress, CHOP/GADD153, which is an apoptotic effector protein situating functionally downstream of the UPR signaling pathways, was also investigated. The basal level of CHOP/GADD153 was extremely low, on exposure to RES Raji and Daudi cells depicted a marked increase in the concentrations of CHOP mRNA (Figure 4A) and protein (Figure 4B) in a dose-dependent manner. In addition, RES treatment also caused dose-dependent cleavage of caspase-4 (Figure 4B), which has been shown to be predominantly located to the outer membrane of the ER, and to play important roles in ER stress-induced apoptosis[31,36,37]. 


\section{Involvement of ER stress in RES-induced cell death}

We therefore examined if RES might actually cause the activation of UPR which in turn caused cell death. MTT analysis showed that treatment of Daudi and Raji cells with RES greatly reduced cell proliferation and viability in a dose-dependent manner (Figure 5A). This inhibitory effect became apparent at a concentration of $20 \mu \mathrm{M}$ RES (Figure 5A). To determine whether the decrease in cell viability was attributable to apoptosis, cells were stained with FITC conjugated Annexin V plus PI and evaluated by FACS. Both Daudi and Raji cells underwent dose-dependent apoptotic cell death in response to RES (Figure 5B).

Since the role of cytosolic $\mathrm{Ca}^{2+}$ as proapoptotic messenger involved in ER stress-mediated apoptosis has been ascertained[38], we investigated whether RES treatment affects cytosolic $\mathrm{Ca}^{2+}$. Addition of RES was found to significantly increase cytosolic $\mathrm{Ca}^{2+}$ (Figure $5 \mathrm{C}$ ). Treatment of cells with the intracellular $\mathrm{Ca}^{2+}$ chelator BAPTA $(10 \mu \mathrm{M}$ for $3 \mathrm{~h})$ prior to RES treatment $(24 \mathrm{~h})$, caused an effective chelation of cytosolic $\mathrm{Ca}^{2+}$ (Figure $5 \mathrm{C})$. Importantly, pretreatment with BAPTA also mitigated apoptosis induced by RES (Figure 5D).

CHOP/GADD153 is one of the components of the ER stress-mediated apoptosis pathway. To further investigate the potential involvement in ER stress-mediated apoptosis by RES, we examined whether induction of CHOP/ GADD153 is critical to induce RES-mediated Burkitt's lymphoma cell death by siRNA duplex against CHOP mRNA. Daudi and Raji cells were transfected with the indicated siRNA were treated with vehicle or RES. Western blot analysis demonstrated that siRNA against CHOP effectively prohibited its upregulation mediated by RES (Figure 5E). Importantly, under these conditions, apoptosis induced by RES was significantly attenuated in Daudi and Raji cells transfected with CHOP siRNA when compared with scramble siRNA or siRNA against mutant CHOP-transfected cells (Figure 5F).

Next we investigated whether RES caused normal lymphocyte death via induction of ER stress. Real-time PCR indicated that in normal B lymphoblast HMy2.CIR cells, RES increased the GRP78/Bip transcript with about 2 folds upon exposure to $100 \mu \mathrm{M}$ of RES (Figure $5 \mathrm{G}$ ). It should be noted that same concentration of RES resulted in 12 and 20 folds of GRP78/Bip induction in Raji and Daudi cells, respectively (4A). Importantly, no obvious induction of CHOP was observed in RES treated HMy2. CIR cells (5G). Consistent with real-time PCR, Western blot demonstrated that GRP78/Bip protein levels were increased upon RES exposure, whereas, CHOP proteins were undetectable in HMy2.CIR cells with or without RES treatment (Figure 5H). Flow cytometry demonstrated that $100 \mu \mathrm{M}$ of RES had no obvious effects on apoptosis of HMy2.CIR cells (Figure 5I).

\section{Discussion}

The use of nontoxic chemical substances is considered a promising alternative strategy for the treatment of human cancer. In recent years, many natural or dietary substances have been shown to inhibit experimental carcinogenesis [39]. In this regard, RES, a phytoalexin found in grapes and peanuts hat has shown promise as a novel chemotherapeutic agent, which exerts a wide array of biological effects, including anti-inflammatory, anti-proliferative and potential chemopreventive activity against human cancer [40]. Moreover, RES has been shown to suppress the growth of transformed cells also through induction of apoptosis[9,41,42]. Over the past decade, RES has emerged as one of the most promising naturally occurring compound with immense therapeutic potential. However, unlike other commonly occurring natural or synthetic drugs, the precise effect and mode of action of RES has remained enigmatic. In this study we tried to establish the pro-apoptotic role of RES in Burkitt's lymphoma cells and to decipher the mechanisms underlying this action. We showed that treatment of Daudi and Raji Burkitt's lymphoma cells with RES was able to induce ER stress and activated all 3 branches of the UPR. It was interesting to note that both the full-length and cleaved ATF6 increased upon RES exposure. Full-length, as well as cleaved ATF6 was also reported to be increased in cells treated with 4 HPR[43]. Since lack of information on the metabolism of these two proteins at the present, the underlying mechanisms remain to be clarified in the future.

The mechanism of ER stress and the unfolded protein response is primarily a cell protective mechanism [44,45], resulting in transient induction of cell cycle arrest and accumulation of molecular chaperons such as GRP78/BiP to bind and recover unfolded proteins. However, it has repeatedly been described that prolonged exposure of cells to either ER stress can induce a switch from cell survival to apoptosis, and the cell protective function of these mechanisms appears to be only a timely restricted protection $[44,46]$. The induction of GADD153/CHOP, synthesized as a downstream component upon the activation of PERK/eIF2a pathway, may be related to the cell death-mediating effect of ER stress. GADD153/CHOP is a proapoptotic protein that is able to downregulate the expression of $\mathrm{Bcl}-2$, and to upregulate the expression of some proapoptotic members of the Bcl-2 family $[47,48]$. Overexpression of GADD153/CHOP has been reported to lead to cell cycle arrest and apoptosis, which are believed to be important targets for cancer drug development[30]. In the current study, we found that RES exposure induced apoptotic executor GADD153/CHOP expression in Raji and Daudi cells. Furthermore, we demonstrated that prohibition of GADD153/CHOP induction attenuated RES-induced cytotoxicity in Raji 

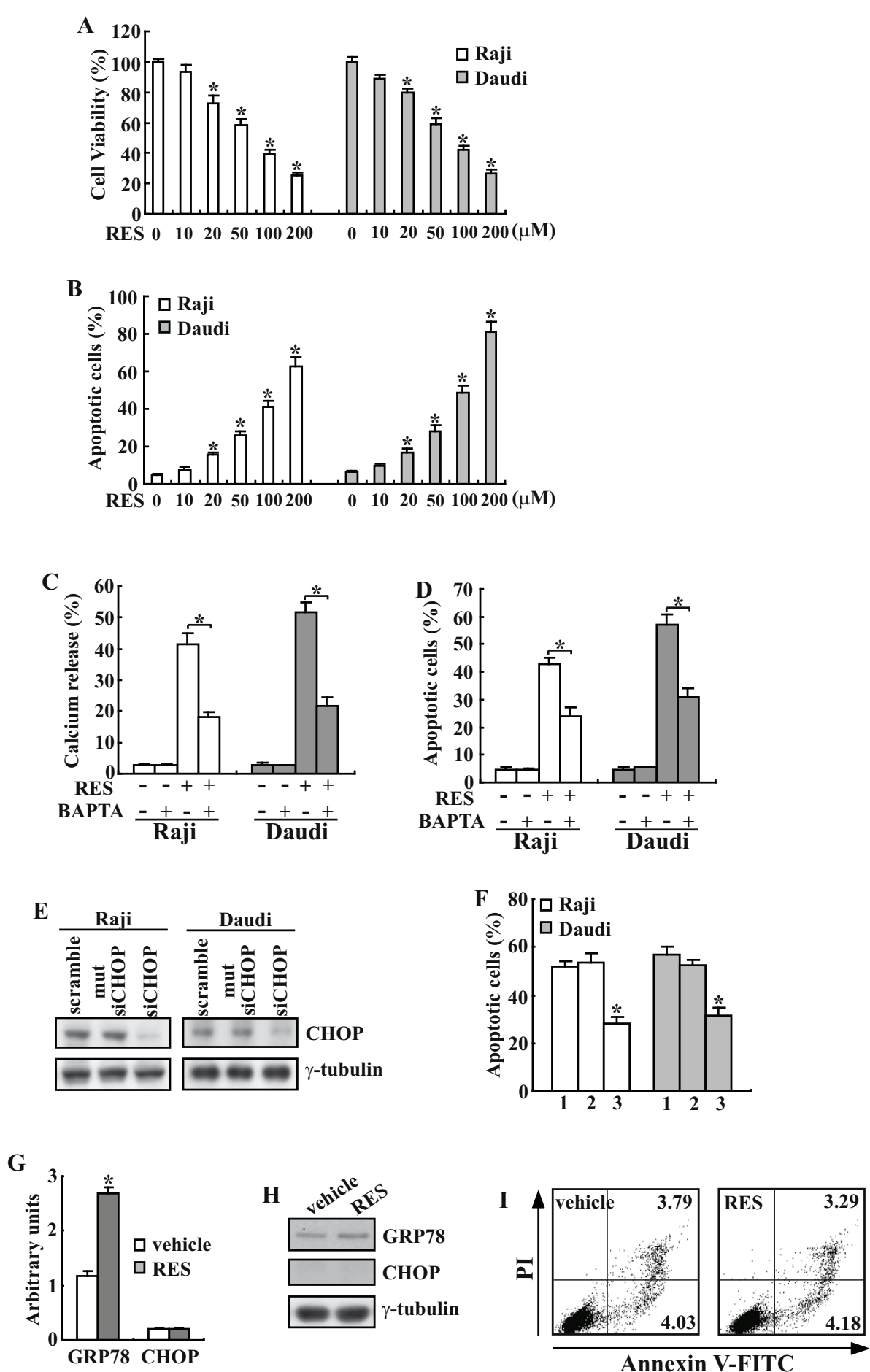

Figure 5 Prohibition of CHOP induction attenuates RES-induced apoptosis in Raji and Daudi cells. Raji and Daudi cells were treated with the indicated concentration of RES for $24 \mathrm{~h}$ and cell viability (A) and apoptotic cells (B) were analyzed using MTT and FACS, respectively. C, Cells were pretreated with vehicle or BAPTA for $3 \mathrm{~h}$, then treated with RES for $24 \mathrm{~h}$ and cytosolic calcium was analyzed using flow cytometry. D, Cells were treated as C, and apoptotic cells were analyzed using Annexin V/PI staining followed by flow cytometry. E, Cells were transfected with scramble, mutant siRNA against CHOP (mutsiCHOP) or siRNA against CHOP (siCHOP) on three consecutive days, treated with $100 \mu \mathrm{M}$ of RES for $24 \mathrm{~h}$ and cell lysates were subjected to Western blotting analysis. F, Cells were treated as C and apoptotic cells were analyzed using FACS. G, HMyc2.CIR cells were treated with indicated concentration of RES for $8 \mathrm{~h}$ and real-time PCR was performed. H, HMyc2.CIR cells were treated with indicated concentration of RES for $24 \mathrm{~h}$ and Western blot analysis was performed. I, HMyc2.CIR cells were treated with $100 \mu \mathrm{M}$ of RES for $24 \mathrm{~h}$, apoptosis of cells was analyzed using flow cytometry. ${ }^{*}, P<0.01$. 
and Daudi cells, suggesting that induction of apoptotic branches of UPR might be implicated in RES-mediated cell cytotoxicity. The activation of UPR by RES was reported in dopaminergic cells recently [18] and data described in this study was provided further insights as to how UPR might be involved in the cytotoxic action of RES in Burkitt's lymphoma cells.

ER is a principal site for protein synthesis and modification prior to directing protein delivery to other organelles and its proper functioning is essential for cell survival. Any external or internal factors, such as calcium store depletion, inhibition of glycosylation, reduction of disulfide bonds, et al., that impinge on ER structure and function will ultimately result in accumulation of unfoled or misfolded proteins, leading to ER stress[20,22]. RES might activate ER stress responses via different mechanisms. For instance, although preferentially functioning as an antioxidant, RES paradoxically has a propensity to stimulate formation of reactive oxygen species (ROS) in some cells [49,50], which can cause oxidation of nascent proteins, thus leading to misfolded proteins and ER stress. It has also been reported that RES inhibits $20 \mathrm{~S}$ proteasomal activity[18], which can cause accumulation of misfolded or unfolded proteins and ER stress. In addition, resveratrol mimics the situation of calorie restriction and ATP deficiency[51], which can hinder proper folding of nascent proteins. Furthermore, red wine polyphenol compounds is reported to increase intracellular calcium[50], suggesting that RES possibly cause ER stress through regulation of calcium store in ER. In the current study, pretreatment with BAPTA for 3 hours dramatically reduced RESinduced apoptosis. Apparently, $\mathrm{Ca} 2+$ plays an important role in RES-induced apoptosis in Burkitt's lymphoma cells. Further deciphering the mechanisms by which RES leads to ER stress in details, might potentiate the combinational treatment using RES and other inducers of ER stress to combat with malignancies.

\section{Conclusions}

RES activates all three branches of UPR in Burkitt's lymphoma cells. In addition, activation of the apoptotic arm of the UPR and its downstream effector CHOP/ GADD153 is involved, at least in part, in RES-induced apoptosis in Burkitt's lymphoma cells.

\footnotetext{
Acknowledgements

This work was partially supported by National Natural Science Foundation of China (30870522) and Shenyang Outstanding Talent Foundation to H-Q Wang.

\section{Author details}

${ }^{1}$ Department of Biochemistry \& Molecular Biology, China Medical University, Shenyang 110001, China. ${ }^{2}$ Department of Radiotherapy, Shenyang Northern
} Hospital, Shenyang 110016, China.

\section{Authors' contributions}

YY carried out the molecular genetic studies, cell culture, and participated in the data analysis. YYG carried out the DNA cloning and flow cytometry. BQL participated in real-time PCR and cell culture. XFN participated in the DNA cloning and cell culture. YZ participated in flow cytometry and MTT assay. HQW conceived of the study, and participated in manuscript drafting and coordinate. All authors read and approved the final manuscript.

\section{Competing interests}

The authors declare that have no competing interests.

Received: 24 March 2010 Accepted: 20 August 2010

Published: 20 August 2010

\section{References}

1. Hammerschmidt R: PHYTOALEXINS: What Have We Learned After 60 Years? Annu Rev Phytopathol 1999, 37:285-306.

2. Signorelli $P$, Ghidoni R: Resveratrol as an anticancer nutrient: molecular basis, open questions and promises. J Nutr Biochem 2005, 16(8):449-466.

3. Gusman J, Malonne H, Atassi G: A reappraisal of the potential chemopreventive and chemotherapeutic properties of resveratrol. Carcinogenesis 2001, 22(8):1111-1117.

4. Jang M, Cai L, Udeani GO, Slowing KV, Thomas CF, Beecher CW, Fong $\mathrm{HH}_{\text {, }}$ Farnsworth NR, Kinghorn AD, Mehta RG, et al: Cancer chemopreventive activity of resveratrol, a natural product derived from grapes. Science 1997, 275(5297):218-220.

5. Kelloff GJ, Crowell JA, Steele VE, Lubet RA, Malone WA, Boone CW, Kopelovich L, Hawk ET, Lieberman R, Lawrence JA, et al: Progress in cancer chemoprevention: development of diet-derived chemopreventive agents. J Nutr 2000, 130(2S Suppl):467S-471S.

6. Athar M, Back JH, Tang X, Kim KH, Kopelovich L, Bickers DR, Kim AL: Resveratrol: a review of preclinical studies for human cancer prevention. Toxicol Appl Pharmacol 2007, 224(3):274-283.

7. Gao X, Xu YX, Divine G, Janakiraman N, Chapman RA, Gautam SC: Disparate in vitro and in vivo antileukemic effects of resveratrol, a natural polyphenolic compound found in grapes. J Nutr 2002, 132(7):2076-2081.

8. Mertens-Talcott SU, Percival SS: Ellagic acid and quercetin interact synergistically with resveratrol in the induction of apoptosis and cause transient cell cycle arrest in human leukemia cells. Cancer Lett 2005 218(2):141-151.

9. Puissant A, Grosso S, Jacquel A, Belhacene N, Colosetti P, Cassuto JP, Auberger $P$ : Imatinib mesylate-resistant human chronic myelogenous leukemia cell lines exhibit high sensitivity to the phytoalexin resveratrol. FASEB J 2008, 22(6):1894-1904.

10. Komina O, Wesierska-Gadek J: Action of resveratrol alone or in combination with roscovitine, a CDK inhibitor, on cell cycle progression in human HL-60 leukemia cells. Biochem Pharmacol 2008, 76(11):1554-1562.

11. Chakraborty PK, Mustafi SB, Ganguly S, Chatterjee M, Raha S: Resveratrol induces apoptosis in K562 (chronic myelogenous leukemia) cells by targeting a key survival protein, heat shock protein 70. Cancer Sci 2008, 99(6):1109-1116.

12. Cecchinato V, Chiaramonte R, Nizzardo M, Cristofaro B, Basile A, Sherbet GV, Comi P: Resveratrol-induced apoptosis in human T-cell acute lymphoblastic leukaemia MOLT-4 cells. Biochem Pharmacol 2007, 74(11):1568-1574.

13. Jeong SH, Jo WS, Song S, Suh H, Seol SY, Leem SH, Kwon TK, Yoo YH: A novel resveratrol derivative, $\mathrm{HS} 1793$, overcomes the resistance conferred by $\mathrm{Bcl}-2$ in human leukemic U937 cells. Biochem Pharmacol 2009, 77(8):1337-1347

14. Aggarwal BB, Bhardwaj A, Aggarwal RS, Seeram NP, Shishodia S, Takada Y: Role of resveratrol in prevention and therapy of cancer: preclinical and clinical studies. Anticancer Res 2004, 24(5A):2783-2840.

15. Fulda S, Debatin KM: Resveratrol modulation of signal transduction in apoptosis and cell survival: a mini-review. Cancer Detect Prev 2006, 30(3):217-223

16. Viswanathan M, Kim SK, Berdichevsky A, Guarente L: A role for SIR-2.1 regulation of ER stress response genes in determining $C$. elegans life span. Dev Cell 2005, 9(5):605-615. 
17. Woo KJ, Lee TJ, Lee SH, Lee JM, Seo JH, Jeong YJ, Park JW, Kwon TK: Elevated gadd153/chop expression during resveratrol-induced apoptosis in human colon cancer cells. Biochem Pharmacol 2007, 73(1):68-76.

18. Chinta SJ, Poksay KS, Kaundinya G, Hart M, Bredesen DE, Andersen JK, Rao RV: Endoplasmic Reticulum Stress-Induced Cell Death in Dopaminergic Cells: Effect of Resveratrol. J Mol Neurosci 2009.

19. Patil C, Walter P: Intracellular signaling from the endoplasmic reticulum to the nucleus: the unfolded protein response in yeast and mammals. Curr Opin Cell Biol 2001, 13(3):349-355.

20. Kaufman RJ: Stress signaling from the lumen of the endoplasmic reticulum: coordination of gene transcriptional and translational controls. Genes Dev 1999, 13(10):1211-1233.

21. Xu C, Bailly-Maitre B, Reed JC: Endoplasmic reticulum stress: cell life and death decisions. J Clin Invest 2005, 115(10):2656-2664.

22. Kaufman RJ: Orchestrating the unfolded protein response in health and disease. J Clin Invest 2002, 110(10):1389-1398.

23. Urano F, Bertolotti A, Ron D: IRE1 and efferent signaling from the endoplasmic reticulum. J Cell Sci 2000, 113(Pt 21):3697-3702.

24. Brewer JW, Diehl JA: PERK mediates cell-cycle exit during the mammalian unfolded protein response. Proc Natl Acad Sci USA 2000, 97(23):12625-12630.

25. Brewer JW, Hendershot LM, Sherr CJ, Diehl JA: Mammalian unfolded protein response inhibits cyclin D1 translation and cell-cycle progression. Proc Natl Acad Sci USA 1999, 96(15):8505-8510.

26. Zinszner $H$, Kuroda M, Wang X, Batchvarova N, Lightfoot RT, Remotti $H$, Stevens $\lrcorner$, Ron D: CHOP is implicated in programmed cell death in response to impaired function of the endoplasmic reticulum. Genes Dev 1998, 12(7):982-995.

27. McCullough KD, Martindale JL, Klotz LO, Aw TY, Holbrook NJ: Gadd153 sensitizes cells to endoplasmic reticulum stress by down-regulating $\mathrm{Bcl} 2$ and perturbing the cellular redox state. Mol Cell Biol 2001, 21(4):1249-1259.

28. Harding HP, Zeng $H$, Zhang $Y$, Jungries $R$, Chung $P$, Plesken $H$, Sabatini DD, Ron D: Diabetes mellitus and exocrine pancreatic dysfunction in perk-/mice reveals a role for translational control in secretory cell survival. $\mathrm{Mol}$ Cell 2001, 7(6):1153-1163.

29. Harding HP, Zhang Y, Bertolotti A, Zeng H, Ron D: Perk is essential for translational regulation and cell survival during the unfolded protein response. Mol Cell 2000, 5(5):897-904.

30. Oyadomari S, Mori M: Roles of CHOP/GADD153 in endoplasmic reticulum stress. Cell Death Differ 2004, 11(4):381-389.

31. Boyce M, Yuan J: Cellular response to endoplasmic reticulum stress: a matter of life or death. Cell Death Differ 2006, 13(3):363-373.

32. Harding HP, Calfon M, Urano F, Novoa I, Ron D: Transcriptional and translational control in the Mammalian unfolded protein response. Annu Rev Cell Dev Biol 2002, 18:575-599.

33. Yoshida H, Okada T, Haze K, Yanagi H, Yura T, Negishi M, Mori K: ATF6 activated by proteolysis binds in the presence of NF-Y (CBF) directly to the cis-acting element responsible for the mammalian unfolded protein response. Mol Cell Biol 2000, 20(18):6755-6767.

34. Yoshida $H$, Haze $K$, Yanagi $H$, Yura $T$, Mori $K$ : Identification of the cis-acting endoplasmic reticulum stress response element responsible for transcriptional induction of mammalian glucose-regulated proteins. Involvement of basic leucine zipper transcription factors. J Biol Chem 1998, 273(50):33741-33749.

35. Shen J, Prywes R: ER stress signaling by regulated proteolysis of ATF6. Methods 2005, 35(4):382-389.

36. Hitomi J, Katayama T, Eguchi Y, Kudo T, Taniguchi M, Koyama Y, Manabe T, Yamagishi S, Bando $Y$, Imaizumi K, et al: Involvement of caspase-4 in endoplasmic reticulum stress-induced apoptosis and Abeta-induced cell death. J Cell Biol 2004, 165(3):347-356.

37. Jiang CC, Chen LH, Gillespie S, Wang YF, Kiejda KA, Zhang XD, Hersey P. Inhibition of MEK sensitizes human melanoma cells to endoplasmic reticulum stress-induced apoptosis. Cancer Res 2007, 67(20):9750-9761.

38. Timmins JM, Ozcan L, Seimon TA, Li G, Malagelada C, Backs J, Backs T, Bassel-Duby R, Olson EN, Anderson ME, et al: Calcium/calmodulindependent protein kinase II links ER stress with Fas and mitochondrial apoptosis pathways. J Clin Invest 2009, 119(10):2925-2941.

39. Kelloff GJ: Perspectives on cancer chemoprevention research and drug development. Adv Cancer Res 2000, 78:199-334
40. Pervaiz S: Resveratrol: from grapevines to mammalian biology. FASEB J 2003, 17(14):1975-1985

41. Ferry-Dumazet $H$, Garnier $O$, Mamani-Matsuda $M$, Vercauteren J, Belloc $F$ Billiard C, Dupouy M, Thiolat D, Kolb JP, Marit G, et al: Resveratrol inhibits the growth and induces the apoptosis of both normal and leukemic hematopoietic cells. Carcinogenesis 2002, 23(8):1327-1333.

42. She QB, Bode AM, Ma WY, Chen NY, Dong Z: Resveratrol-induced activation of $\mathrm{p} 53$ and apoptosis is mediated by extracellular-signalregulated protein kinases and p38 kinase. Cancer Res 2001, 61(4):1604-1610

43. Lai WL, Wong NS: The PERK/elF2 alpha signaling pathway of Unfolded Protein Response is essential for N-(4-hydroxyphenyl)retinamide (4HPR)induced cytotoxicity in cancer cells. Exp Cell Res 2008, 314(8):1667-1682.

44. Lin JH, Li H, Yasumura D, Cohen HR, Zhang C, Panning B, Shokat KM, Lavail MM, Walter P: IRE1 signaling affects cell fate during the unfolded protein response. Science 2007, 318(5852):944-949.

45. Wek RC, Jiang HY, Anthony TG: Coping with stress: elF2 kinases and translational control. Biochem Soc Trans 2006, 34:(Pt 1):7-11.

46. Debnath J, Baehrecke EH, Kroemer G: Does autophagy contribute to cell death? Autophagy 2005, 1(2):66-74.

47. Boya P, Morales MC, Gonzalez-Polo RA, Andreau K, Gourdier I, Perfettini JL, Larochette N, Deniaud A, Baran-Marszak F, Fagard R, et al: The chemopreventive agent $\mathrm{N}$-(4-hydroxyphenyl)retinamide induces apoptosis through a mitochondrial pathway regulated by proteins from the Bcl-2 family. Oncogene 2003, 22(40):6220-6230.

48. Lovat PE, Oliverio S, Corazzari M, Rodolfo C, Ranalli M, Goranov B, Melino G, Redfern CP, Piacentini M: Bak: a downstream mediator of fenretinideinduced apoptosis of SH-SY5Y neuroblastoma cells. Cancer Res 2003, 63(21):7310-7313.

49. Tinhofer I, Bernhard D, Senfter M, Anether G, Loeffler M, Kroemer G, Kofler R, Csordas A, Greil R: Resveratrol, a tumor-suppressive compound from grapes, induces apoptosis via a novel mitochondrial pathway controlled by Bcl-2. FASEB J 2001, 15(9):1613-1615

50. Duarte J, Andriambeloson E, Diebolt M, Andriantsitohaina R: Wine polyphenols stimulate superoxide anion production to promote calcium signaling and endothelial-dependent vasodilatation. Physiol Res 2004, 53(6):595-602

51. Smith JJ, Kenney RD, Gagne DJ, Frushour BP, Ladd W, Galonek HL, Israelian K, Song J, Razvadauskaite G, Lynch AV, et al: Small molecule activators of SIRT1 replicate signaling pathways triggered by calorie restriction in vivo. BMC Syst Biol 2009, 3:31.

\section{Pre-publication history}

The pre-publication history for this paper can be accessed here: http://www.biomedcentral.com/1471-2407/10/445/prepub

\section{doi:10.1186/1471-2407-10-445}

Cite this article as: Yan et al:: Resveratrol-induced cytotoxicity in human Burkitt's lymphoma cells is coupled to the unfolded protein response. BMC Cancer 2010 10:445.

\section{Submit your next manuscript to BioMed Central and take full advantage of:}

- Convenient online submission

- Thorough peer review

- No space constraints or color figure charges

- Immediate publication on acceptance

- Inclusion in PubMed, CAS, Scopus and Google Scholar

- Research which is freely available for redistribution

Submit your manuscript at www biomedcentral.com/submit
Biomed Central 